\title{
The role of perceived stress and cognitive function on the relationship between neuroticism and depression among the elderly: a structural equation model approach
}

Mukda Banjongrewadee ${ }^{1}$, Nahathai Wongpakaran ${ }^{1 *}$, Tinakon Wongpakaran', Tanyong Pipanmekaporn², Yodying Punjasawadwong ${ }^{2}$ and Sirirat Mueankwan ${ }^{3}$

\begin{abstract}
Background: Depression comprises common psychological problems, and has been strongly related to neuroticism and perceived stress. While neuroticism has been shown to have a direct effect on depression, it also has an indirect effect via perceived stress. Among the elderly, cognitive function produces influences that should not be overlooked when investigating depression. This study aimed to determine the role of mediating effects of perceived stress as well as cognitive function on neuroticism and depression among elderly patients.
\end{abstract}

Methods: This research constituted a secondary analysis, with data collected during the pre-operative period of 429 elderly individuals undergoing elective, noncardiac surgery. The evaluation included the Perceived Stress Scale, the Neuroticism Inventory, the Montreal Cognitive Assessment, and the Geriatric Depression Scale. Structural equation modeling was used to investigate the hypothesized model.

Results: Neuroticism exhibited a significant indirect effect on perceived stress via depression and cognition ( $\beta=$ $0.162,95 \% \mathrm{Cl} 0.026,0.322, p=.002)$. Neuroticism initially had a direct effect on depression $(\beta=0.766,95 \% \mathrm{Cl} 0.675$, $0.843 p=0.003)$; thereafter, it was reduced after covariates were added $(\beta=0.557,95 \% \mathrm{Cl} 0.432,0.668 p=0.002)$. Based on this model, the total variance explained by this model was $67 \%$, and the model showed an acceptable fit with the data.

Conclusions: Both perceived stress and cognitive function partially mediated the effect of neuroticism on depression, with perceived stress exhibiting a greater effect.

Trial registration: The study protocol has been registered at Clinicaltrials.gov under registered number: NCT02131181.

\footnotetext{
* Correspondence: nahathai.wongpakaran@cmu.ac.th

${ }^{1}$ Geriatric Psychiatry Unit, Department of Psychiatry, Faculty of Medicine, Chiang Mai University, 110 Intawaroros Rd., T. Sriphum, A. Muang, Chiang Mai 50200, Thailand

Full list of author information is available at the end of the article
}

(c) The Author(s). 2020 Open Access This article is distributed under the terms of the Creative Commons Attribution 4.0 International License (http://creativecommons.org/licenses/by/4.0/) which permits unrestricted use, distribution, and reproduction in any medium, provided you give appropriate credit to the original author(s) and the source, provide a link to the Creative Commons license, and indicate if changes were made. The Creative Commons Public Domain Dedication waiver (http://creativecommons.org/publicdomain/zero/1.0/) applies to the data made available in this article, unless otherwise stated. 


\section{Background}

Depression among the elderly is associated with various risk factors, including personality traits such as neuroticism. Neuroticism, which is one of the Big Five higherorder personality traits, represents the tendency to experience negative emotions, such as anxiety and anger, leading to susceptibility to psychological distress and vulnerability to stress [1]. Neuroticism is associated with negative emotions such as anxiety, fear, and anger [2].

There is a well-established relationship between neuroticism and depression, particularly among the elderly. Previous research has found that $15-25 \%$ of elderly persons experience high levels of neuroticism [3, 4].

On the one hand, the perception of stress following stressful life events conceivably precedes the development of depression, a process which is well-documented in the clinical literature [5-9]. Perceived stress involves the feelings or thoughts that individuals have regarding the extent of the stress they are experiencing at a given time. Perceived stress is significant for its biological, emotional, and physical consequences, including cardiovascular disorders, diseases related to poor immunological function, sleep problems and depression [8-18].

Perceived stress is one of the top five psychological health problems among elderly people in the US [19]. Among the elderly, perceived stress seems to be higher than it is in younger adults [20]. Relevant studies have revealed that the level of stress increases in relation to age in a linear fashion [20].

Perceived stress is closely related to neuroticism to the extent that they each constitute different facets [21]; however, a recent study suggested that perceived stress is not representative of neuroticism [22]. Neuroticism is one of the well-established predictors of perceived stress and depression [18, 23-26].

In terms of the relationship between neuroticism and perceived stress, higher neuroticism may promote negative emotional regulation or maladaptive reactivity to stress, which increases the predisposition to depressive symptoms. At the same time, studies have shown that perceived stress mediates the relationship between neuroticism and depression, serving to reduce the effect of neuroticism on depression [5, 27, 28]. However, both these studies were conducted in young and adult populations, rather than elderly participants. As such, there is a need for research addressing the relationship between these variables in elderly populations.

Cognitive function plays an important role in the interrelationships of neuroticism, depression, and perceived stress in elderly populations. The relationship between cognitive impairment and depression is well established [29]. Interestingly, perceived stress is related to lower initial cognitive scores and a faster rate of cognitive decline among adults aged 65 and above [30-33].
A recent study reported that perceived stress was a unique and modifiable risk factor for normal and pathological cognitive aging [34].

Another interesting relationship is that between cognition and neuroticism. Studies have demonstrated that high neuroticism is a risk factor for the development of cognitive impairment and dementia among the elderly [35-37]. Neuroticism is associated with cognitive function in most studies that use cross-sectional data. The results from longitudinal studies are inconsistent; nevertheless, majority of longitudinal studies (8/11) supported a relationship between neuroticism and cognitive function [38, 39].

Given the fact that cognitive function tends to decline with age, and the fact that the elderly are also more vulnerable to increased stress and neuroticism [39], elderly people may be particularly vulnerable to depression. There is an absence of studies including cognitive function in the mediation model of the relationship between depression, neuroticism, and perceived stress. It is not clear how these factors would come into play in depression among elderly people. To the best of our knowledge, no studies to date have addressed this issue.

In this study, we sought to investigate the relationship between these variables in a sample of elderly subjects. Moreover, we hypothesized that cognitive function would act as a mediator in the relationship between neuroticism and depression. Based on the reviewed evidence, we formed two hypotheses. First, both perceived stress and cognitive function would serve as mediators of the relationship between neuroticism and depression. Second, perceived stress would be associated with cognitive function, but more closely related to depression. We then hypothesized (in the multiple mediation model) that the indirect effect of neuroticism on depression via perceived stress would be characterized by a larger effect size than the indirect effect of neuroticism on depression via cognitive function.

\section{Materials and methods}

This was a part of the study on the incidence of Postoperative delirium (POD) among 429 elderly individuals undergoing elective, noncardiac surgery. It was a crosssectional analysis during their pre-operative period at a university hospital in northern Thailand between December 2013 and November 2014. An independent ethics committee approved this study's ethics, and written informed consent forms were obtained from participants involved in the primary study. The study protocol has been registered at Clinicaltrials.gov under registered number: NCT02131181.

\section{Participants}

The study included participants 60 years of age or older who were scheduled for elective noncardiac surgery. 
They were classified as American Society of Anesthesiologists (ASA) physical statuses I, II and III and provided informed consent. Older individuals with severe hearing/ visual loss or dementia were excluded from the study. Those who were unable to communicate in Thai were also excluded. The participants provided information on the following: demographics, surgical diagnoses, surgery type, anesthetic technique, psychiatric/substance conditions and psychiatric assessments. The psychiatric assessments included the Perceived Stress Scale (PSS-10), the Neuroticism Inventory (NI), the Montreal Cognitive Assessment (MoCA) and the Geriatric Depression Scale (GDS-15). All measurements involved Thai versions. The diagnosis of dementia was made by psychiatrist investigators, while research assistants administered MoCA tests for all participants, and assisted in the process of participants' administering self-reporting questionnaires. The present study excluded 80 participants due to the exclusion criteria. A total of 349 study subjects were included in the final analysis.

\section{Measurements \\ 10-item perceived stress scale (PSS-10)}

This scale is a 10-item self-report using a 5-point Likert scale format $(0=$ never to $4=$ very often $)$, and the total score ranges from 0 to 40 [40]. Higher scores indicate greater perceived stress. The Thai version demonstrated good reliability and validity and has been widely used for adults; and specifically, for the elderly [41].

\section{Neuroticism inventory (NI)}

The NI is a dimensional measure of the neuroticism personality trait based on Eysenck's five-factor model [23]. The NI, developed by Wongpakaran et al., consists of a self-rating scale that includes 15 items with a 0 to 4 Likert scale [42]. A higher score reflects a higher level of neuroticism. Cronbach's alpha was 0.83 . Its validity was similar to that of the Thai Depression Inventory, the State-Trait Anxiety Inventory, the Multi-dimensional Scale of Perceived Social Support (MSPSS) and the Inventory of Interpersonal Problems. Its correlation coefficients are $0.0 .61,-0.23,0.52$, and 0.60 , respectively $(p<$ 0.001 for all).

\section{Montreal cognitive assessment (MoCA)}

The MoCA cognitive test evaluates 11 cognitive functions and the Thai version was used [43]. This test can be completed in $10 \mathrm{~min}$ [44]. The total score is 30 , and the cut-off score for cognitive impairment is 25. Cronbach's alpha coefficient was 0.74 , Pearson's correlation coefficient was 0.91 , sensitivity was $70 \%$, and specificity was 95\% [45]. However, in ROC curve analysis to determine the optimal cut-off score of MoCA against Mental State Examination T10 (a modified Thai version of
MMSE 2002) [46], the cut-off score 12/13 was suggested by Youden's Index to detect dementia. This cut-off score yielded a sensitivity of 83.33 (95\%CI, 70.7-92.40), and specificity of 82.40 (95\%CI, 78.2-86.1). Area under the ROC curve $(\mathrm{AUC})=0.914(0.0171)(95 \% \mathrm{CI}, 0.884-0.939)$, with a $p$ value <.0001. Therefore, 80 subjects, who scored MoCA below 13, were excluded for analysis.

\section{The 15-item geriatric depression scale (GDS-15)}

The GDS-15 is a widely used self-rating assessment tool that measures depressive symptoms among the elderly [47]. The Thai version shows a good internal consistency (Cronbach's alpha was 0.85) [48].

\section{Statistical analyses}

The scores of the PSS-10, NI, MoCA and GDS-15 were reported using descriptive statistics. The correlation between PSS-10, NI, MoCA, and GDS-15 was analyzed to confirm the association among variables, which was appropriate for a mediation model. IBM SPSS, Version 22 was used for this analysis.

To examine the relationship among variables, we used SEM comprising a measurement model and the structural model. SEM used latent variables to account for measurement error of the scales, i.e., of neuroticism, depression and perceived stress, and to specify the relationships among latent variables, while path analysis using observed variable (total score) assumes that all variables are measured without error. For MoCA, observe score was used as it was a composite score.

For the structural equation model (SEM), we created three parcels for neuroticism and two parcels for depression and PSS. We determined each as parcels 1, 2, or 3 according to the loading coefficients. We tested each measurement model and assessed the parcel and subscale loadings on the latent constructs before testing the SEM. The model fit was assessed using standard $\chi^{2}$ fit statistics, the Comparative Fit Index (CFI), the TuckerLewis index (TLI), and the root mean square error of approximation (RMSEA). A CFI and TLI greater than 0.95 and a RMSEA less than 0.06 indicated a good model fit. Because $\chi^{2}$ statistics are sensitive to sample size, we used the ratio of $x^{2} / \mathrm{df}<3$ as an acceptable model fit.

Because latent variables were used instead of observed variables, the latent mediation structural equation model was applied using full information maximum likelihood with robust standard errors. It was also used to assess the latent SEM. Data were checked for normality, outliers and multicollinearity before conducting CFA and SEM. A multiple imputation method was used to correct missing data. In each SEM, 21 parameters needed to be estimated. The ratio of sample size to the number of parameters to be estimated was approximately 20:1, which was 
acceptable. In approaches to investigate the mediating effect of depression and cognition on the relationship between neuroticism and perceived stress, the following significant correlations should be established: between neuroticism and cognition, between cognition (depression) and perceived stress and between neuroticism and perceived stress controlling cognition (depression) [49]. The total indirect effect of neuroticism on cognition and depression was analyzed. Age and sex were controlled for each mediation model and bias-corrected bootstrapping was applied for testing indirect effects.

\section{Results}

The study consisted of 349 participants: 149 males $(42.7 \%)$ and 200 females (57.3\%). The mean age was $69.15 \pm 6.38$ years old. The mean educational attainment was $7.07 \pm 5.16$ years $($ median $=4$, mode $=4$ ). The vast majority reasons for surgery was malignant neoplasm (33.0\%). The most common co-morbidity was hypertension (54.44\%). The means of the PSS, NI, MoCA, and GDS-15 scores are shown in Table 1.

Table 1 Demographics and clinical characteristics of participants

\begin{tabular}{|c|c|c|}
\hline Characteristics $(n=349)$ & $\begin{array}{l}\text { Value } \mathrm{n}(\%) \text { or mean } \\
\text { (SD) }\end{array}$ & Range \\
\hline Sex, Female & $200(57.3)$ & \\
\hline Age, years & $69.15(6.38)$ & $60-86$ \\
\hline Years of education & $7.07(5.16)$ & $0-23$ \\
\hline \multicolumn{3}{|l|}{ Main Physical illness for surgery } \\
\hline Malignant neoplasm & $115(33.0)$ & \\
\hline Primary gonarthrosis & $34(9.7)$ & \\
\hline Calculus of gall bladder & $32(9.2)$ & \\
\hline Fracture & $20(5.7)$ & \\
\hline Benign neoplasm & $19(5.4)$ & \\
\hline Inguinal hernia & $13(3.7)$ & \\
\hline Uterovaginal prolapse & $10(2.9)$ & \\
\hline \multicolumn{3}{|l|}{ Co-morbidities } \\
\hline Hypertension & $190(54.44)$ & \\
\hline Diabetes Mellitus & $45(12.89)$ & \\
\hline Renal disease & $41(11.75)$ & \\
\hline $\begin{array}{l}\text { Chronic obstructive pulmonary } \\
\text { disease }\end{array}$ & $12(3.44)$ & \\
\hline Ischemic heart disease & $21(6.02)$ & \\
\hline PSS-10 & $12.45(5.33)$ & $0-27$ \\
\hline $\mathrm{NI}$ & $30.87(9.22)$ & $15-57$ \\
\hline MoCA & $18.25(3.71)$ & $13-29$ \\
\hline GDS-15 & $3.57(2.29)$ & $0-13$ \\
\hline
\end{tabular}

Abbreviations: $n$ Number, SD Standardized deviation, PSS-10 10-item Perceived Stress Scale, NI Neuroticism inventory, MoCA Montreal Cognitive Assessment, GDS-15 15-item Geriatric Depression Scale
Pearson product moment correlation coefficients between each variable are presented in Table 2 . As can be seen in Table 2, these correlation coefficients ranged from nil to moderate (.015-.610). Two points are worth mentioning regarding these correlations. First, a significant correlation was found between MoCA, GDS, NI, and PSS. The magnitude of the correlations between GDS and NI was the largest $(r=.554, p<.001)$. MoCA had a significant negative correlation with GDS, NI, and PSS. Second, demographic data especially MoCA had significant correlation with the interested variables by that males had significant, albeit low, correlation with education, and education was related to MoCA, GDS, and NI. As expected, advancing age negatively correlated with cognitive function assessed by MoCA. Therefore, demographic data were accounted for in the SEM.

\section{Testing for a mediation model}

After controlling for sex, age and education, the hypothesized multiple mediator model (Fig. 1) showed that neuroticism exhibited an indirect effect on depression via perceived stress and cognitive function $(\beta=0.162,95 \% \mathrm{CI}$ [0.026, 0.322], $p=.002)$. Separately, neuroticism had a significant indirect effect on depression via cognition alone ( $\beta=0.036,95 \% \mathrm{CI}[0.020,0.063], p=0.001$ ), while neuroticism had a significant indirect effect on depression via perceived stress alone $(\beta=0.134,95 \%$ CI $[0.062,0.210]$, $p=0.003)$. This supported our first hypothesis.

Overall, neuroticism initially had a direct effect on depression ( $\beta=0.766,95 \% \mathrm{CI}[0.675,0.843], p=0.003$ ), which was reduced $(\beta=0.557,95 \%$ CI $[0.432,0.668], p=0.002)$ after all covariates were held constant. However, the direct effect of cognitive function on perceived stress was nonsignificant ( $\beta=-0.05,95 \% \mathrm{CI}[-.146,0.036], p=0.344)$.

The model demonstrated an acceptable fit for the data: $\mathrm{CFI}=0.983$, TLI $=0.972$, RMSEA $=0.041$ (90\% CI $[.017$, $.061]), \mathrm{X}^{2}=52.35, \mathrm{df}=33, p=.017, \mathrm{X}^{2} / \mathrm{df}=1.59$.

In the decomposition of the model, $64.0 \%$ of the variance in perceived stress was accounted for when depressive symptoms served as a mediator. When cognition was

Table 2 Correlation matrix between variables

\begin{tabular}{llllllll}
\hline & Age & Sex & Education & MoCA & GDS & NI & PSS \\
\hline Age & 1 & & & & & & \\
Sex & -.031 & 1 & & & & & \\
Education & -.096 & $.168^{\mathrm{a}}$ & 1 & & & & \\
MoCA & $-.199^{\mathrm{a}}$ & .100 & $.610^{\mathrm{a}}$ & 1 & & \\
GDS & -.015 & -.067 & $-.234^{\mathrm{a}}$ & $-.305^{\mathrm{a}}$ & 1 & & \\
NI & -.094 & -.028 & $-.270^{\mathrm{a}}$ & $-.293^{\mathrm{a}}$ & $.554^{\mathrm{a}}$ & 1 & \\
PSS & -.018 & -.033 & -.089 & $-.195^{\mathrm{a}}$ & $.453^{\mathrm{a}}$ & $.363^{\mathrm{a}}$ & 1 \\
\hline
\end{tabular}

PSS-10 10-item Perceived Stress Scale, NI Neuroticism inventory, MoCA Montreal Cognitive Assessment, GDS-15 15-item Geriatric Depression Scale ${ }^{\text {a }}$ Correlation is significant at the 0.01 level (2-tailed) 


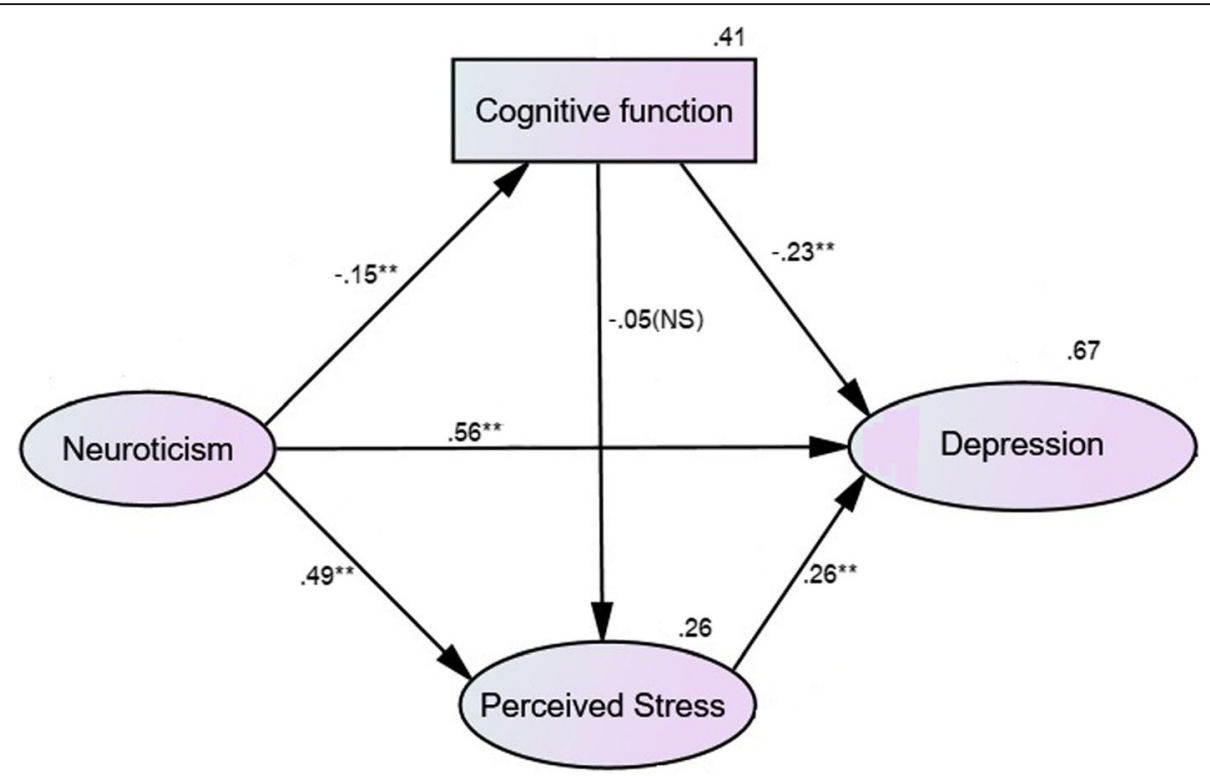

Fig. 1 The standardized estimates of the hypothesized model. Legend: rectangular = observed variable, oval = latent variable, number on variable $=$ R square value. ${ }^{*} p<.05,{ }^{* *} p<.01, \mathrm{NS}=$ nonsignificant

added as the second mediator, this multiple mediator model explained $67.3 \%$ of the variance in depression.

As cognitive impairment may correlate with perceived stress and/or neuroticism, we also tested an alternative model by having cognitive function serve as a precursor of neuroticism, perceived stress and depression. Thus, cognitive function was treated as an exogenous variable, while neuroticism and perceived stress were treated as endogenous variables (only the path between cognitive function and perceived stress was oppositely redirected). The structural equation modeling analysis showed similar results to those hypothesized in the original model, for which chi-square was $52.39(\mathrm{df}=33), \mathrm{CFI}=.983$, $\mathrm{TLI}=.972$ and RMSEA 0.41 (90\% CI [.018-, .061]). The extent to which these variables accounted for the variance in depression was the same (67\%). However, the path coefficient between neuroticism and cognitive function became non-significant as it was mediated by perceived stress $(\beta=0.083,95 \%$ CI $[-.169,0.010], p=$ 0.123). This supported our second hypothesis. Based on theory and empirical evidence, personality traits such as neuroticism do not change markedly during the course of life, while cognitive function does change as a result of age, stress and depression. Hence, the original hypothesized model was more suitable than the alternative model and became the final hypothesized model.

\section{Discussion}

The present study investigated the extent to which neuroticism, perceived stress and cognitive function influenced depression. Both of our hypotheses were confirmed and, consistent with related studies on adults, we found that these variables had a significant effect in elderly people [27, $28,50,51]$. That is, the present findings suggested that both perceived stress and cognitive function act as a mediator between neuroticism and depression in elderly people.

A few points from this study may serve to broaden our current knowledge. Firstly, by adding cognitive function to the multiple mediator model, the variance in depression can be better explained, suggesting that there is an effect of cognition on depression among the elderly. A recent study revealed that the association between neuroticism and cognitive function may be mediated by negative affect [39], and evidence indicated that negative affect was linked to perceived stress [52-54]. However, an extensive review by Curtis et al. found inconsistent results in regard to the relationship between neuroticism and cognition [38]. Most of the studies reporting a significant relationship between neuroticism and cognition using either cross-sectional or longitudinal data; some did not find such a relationship. It is interesting that the pattern in the hypothesized model (with a small but significant relationship between neuroticism and cognitive function) disappeared in the alternative model, where the path was redirected from perceived stress to cognition. The non-significant reverse models provide empirical support for the directionality of the hypothesized indirect effects of neuroticism via perceived distress on cognitive function. In other words, perceived stress mediated the relationship between neuroticism and cognition. This finding suggests that it is worth including perceived stress as a variable in further studies exploring the relationship between neuroticism and cognition, whether they be cross-sectional or longitudinal. 
Previous studies have indicated the existence of the relationship between neuroticism, perceived stress, and depression in elderly people with clinical depressive disorder $[55,56]$, and the present study supports the existence of such relationships among elderly people without clinically diagnosed depressive disorders. This might apply to the elderly at similar pre-operative periods (or in related clinical settings) as a means of mitigating the severity of depressive symptom, heightened perceived stress, or cognitive decline following operations which typically lead to increased morbidity or prolonged hospitalization [57].

The final point we would like to highlight is that this multiple mediator model explained up to $67 \%$ of the variance in depression, while cognitive function explained only $3 \%$. Although this effect may seem minimal, recall that we measured global cognitive function using the Montreal Cognitive Assessment (MoCA). Neuroticism may have had an effect on specific cognitive domains such as perceptual speed, working and episodic memory, and fluid ability [39, 58, 59], and this effect may be worth further investigation because the magnitude of association between neuroticism and some specific cognitive domain may vary. Furthermore, it would be ideal to conduct a longitudinal analysis, trait neuroticism is found to be relatively stable [60-62]. Hence, it could be posited as a precursor to be identified in the elderly in a clinical setting, while perceived stress and depression are less stable variables which are prone to change over time. Neuroticism may have temporal precedence over the other two variables [63]. Cognitive function, which appeared to be a mediator of the relationship between neuroticism and depression, is usually assessed in older adults. Poor cognitive function can worsen depressive symptoms in the elderly [64]. Cognitive stimulation is usually provided for patients with mild cognitive impairment, especially in geriatric clinics $[29,65]$. However, as a predictor of depression, cognitive function is overshadowed by perceived stress. Clinicians should aim to plan for both cognitive improvement and stress reduction, particularly among those individuals who exhibit high levels of neuroticism at the screening phase or during the pre-operative period.

\section{Strengths and limitations}

To the best of our knowledge, this is one of the first studies to assess for a relationship between depression, neuroticism, perceived stress and cognition in older adults. This study has several limitations. It was conducted with a small sample size, during a pre-operative period. Thus, the generalizability of this study's findings to the entire elderly population is limited. Replications of this study in the general population or for a specific population of interest are strongly encouraged. Due to its cross-sectional design, this study cannot demonstrate any cause-effect relationships. However, this snapshot of cross-sectional data paves the way for a longitudinal data analysis. Moreover, these cross-sectional results could set the stage for a more carefully delineated design addressing some unanswered questions, including the impact of different types of cognitive function on depression.

Lastly, depression scores from self-report geriatric depression scales may not represent clinical depression as diagnosed by the DSM-5. In future studies, clinical diagnoses should be used to provide more clinical benefit.

\section{Abbreviations}

CFI: Comparative Fit Index; GDS: Geriatric depression scale; MoCA: Montreal cognitive assessment; MSPSS: Multi-dimensional Scale of Perceived Social Support; NI: Neuroticism inventory; POD: Post-operative delirium; PSS: Perceived Stress Scale; RMSEA: Root mean square error of approximation; SEM : Structural equation modeling; TLI: Tucker-Lewis index

\section{Acknowledgements}

This study was part of The Incidences, Long Term Outcomes and Factors Related to Noncardiac Postoperative Delirium among Elderly Patients - POD Program).

\section{Authors' contributions}

NW, MB, TW, TP, and YP conceived and designed the study. SM co-designed and collected data. Statistical analysis was performed by NW, TW, and MB. All authors wrote the manuscript and approved the final version.

\section{Funding}

POD program was funded by the National Research Council of Thailand. The funder had no role in study design, data collection, analysis, interpretation of the data, decision to publish, or preparation of the manuscript.

\section{Availability of data and materials}

The datasets generated and/or analysed during the current study are not publicly available due to ethics approval but are available from the corresponding author on reasonable request.

\section{Ethics approval and consent to participate}

An independent ethics committee of Faculty of Medicine, Chiang Mai University approved this study's ethics. Written informed consent was obtained from all participants included in the study.

\section{Consent for publication}

Not applicable.

\section{Competing interests}

The authors declare that they have no competing interests.

\section{Author details}

${ }^{1}$ Geriatric Psychiatry Unit, Department of Psychiatry, Faculty of Medicine, Chiang Mai University, 110 Intawaroros Rd., T. Sriphum, A. Muang, Chiang Mai 50200, Thailand. 'Department of Anesthesiology, Faculty of Medicine, Chiang Mai University, Chiang Mai, Thailand. ${ }^{3}$ Division of Surgical Critical Care and Trauma, Department of Surgery, Maharaj Nakorn Chiang Mai Hospital, Chiang Mai, Thailand.

Received: 29 March 2019 Accepted: 10 January 2020

Published online: 20 January 2020

\section{References}

1. Francis $L$, Brown $L B$, Philipchalk R. The development of an abbreviated form of the revised Eysenck personality questionnaire (EPQR-A): its use among students in England, Canada, the U.S.A. and Australia. Personal Individ Differ. 1992;13(4):443-9.

2. McCrae RR, Costa PT. Validation of the five-factor model of personality across instruments and observers. J Pers Soc Psychol. 1987;52(1):81-90. 
3. Jurczak A, Szkup M, Wieder-Huszla S, Grzywacz A, Samochowiec A, Karakiewicz B, Samochowiec J, Grochans E. The assessment of the relationship between personality, the presence of the $5 \mathrm{HTT}$ and MAO-A polymorphisms, and the severity of climacteric and depressive symptoms in postmenopausal women. Arch Womens Ment Health. 2015;18(4):613-21.

4. Nordfjærn T, Bjerkeset O, Moylan S, Berk M, Gråwe RW. Clusters of personality traits and psychological symptoms associated with later benzodiazepine prescriptions in the general population: the HUNT cohort study. Addict Behav. 2013;38(10):2575-80.

5. Pereira-Morales A, Adan A, Forero D. Perceived stress as a mediator of the relationship between neuroticism and depression and anxiety symptoms; 2017.

6. Pizzagalli DA, Bogdan R, Ratner KG, Jahn AL. Increased perceived stress is associated with blunted hedonic capacity: potential implications for depression research. Behav Res Ther. 2007:45(11):2742-53.

7. Ray S. Perceived stress and depression among elderly people residing at old age home, vol. 7; 2016.

8. Vasunilashorn S, Glei DA, Weinstein M, Goldman N. Perceived stress and mortality in a Taiwanese older adult population. Stress. 2013;16(6):600-6

9. Zannas AS, McQuoid DR, Steffens DC, Chrousos GP, Taylor WD. Stressful life events, perceived stress, and 12-month course of geriatric depression: direct effects and moderation by the 5-HTTLPR and COMT Val158Met polymorphisms. Stress. 2012;15(4):425-34.

10. Rueggeberg $R$, Wrosch C, Miller GE. The different roles of perceived stress in the association between older adults' physical activity and physical health. Health Psychol. 2012;31(2):164-71.

11. Keller A, Litzelman K, Wisk LE, Maddox T, Cheng ER, Creswell PD, Witt WP. Does the perception that stress affects health matter? The association with health and mortality. Health Psychol. 2012;31(5):677-84.

12. Schlotz W, Yim IS, Zoccola PM, Jansen L, Schulz P. The perceived stress reactivity scale: measurement invariance, stability, and validity in three countries. Psychol Assess. 2011;23(1):80-94.

13. O'Neal WT, Qureshi W, Judd SE, Glasser SP, Ghazi L, Pulley L, Howard VJ, Howard G, Soliman EZ. Perceived stress and atrial fibrillation: the REasons for geographic and racial differences in stroke study. Ann Behav Med. 2015; 49(6):802-8.

14. Glei DA, Goldman N, Shkolnikov VM, Jdanov D, Shkolnikova M, Vaupel JW, Weinstein M. Perceived stress and biological risk: is the link stronger in Russians than in Taiwanese and Americans? Stress. 2013;16(4):411-20.

15. Stewart MG, Davies HA, Sandi C, Kraev IV, Rogachevsky W, Peddie CJ, Rodriguez JJ, Cordero Ml, Donohue HS, Gabbott PL, et al. Stress suppresses and learning induces plasticity in CA3 of rat hippocampus: a threedimensional ultrastructural study of thorny excrescences and their postsynaptic densities. Neuroscience. 2005;131(1):43-54.

16. Mohamadi Hasel K, Besharat MA, Abdolhoseini A, Alaei Nasab S, Niknam S Relationships of personality factors to perceived stress, depression, and oral lichen planus severity. Int J Behav Med. 2013;20(2):286-92.

17. Wongpakaran $T$, Wongpakaran N, Pinyopornpanish M, Srisutasanavong U, Lueboonthavatchai P, Nivataphand R, Apisiridej N, Petchsuwan D, Saisavoey $\mathrm{N}$, Wannarit K, et al. Baseline characteristics of depressive disorders in Thai outpatients: findings from the Thai study of affective disorders. Neuropsychiatr Dis Treat. 2014;10:217-23.

18. Hayward RD, Taylor WD, Smoski MJ, Steffens DC, Payne ME. Association of five-factor model personality domains and facets with presence, onset, and treatment outcomes of major depression in older adults. Am J Geriatr Psychiatry. 2013;21(1):88-96.

19. Payne C, Hedberg EC, Kozloski M, Dale W, McClintock MK. Using and interpreting mental health measures in the National Social Life, health, and aging project. J Gerontol B Psychol Sci Soc Sci. 2014;69(Suppl 2):S99-116.

20. Osmanovic-Thunström A, Mossello E, Åkerstedt T, Fratiglioni L, Wang H-X. Do levels of perceived stress increase with increasing age after age 65? A population-based study. Age Ageing. 2015;44(5):828-34.

21. McCrae RR. Controlling neuroticism in the measurement of stress. Stress Med. 1990;6(3):237-41.

22. Rietschel L, Zhu G, Kirschbaum C, Strohmaier J, Wüst S, Rietschel M, Martin NG. Perceived stress has genetic influences distinct from neuroticism and depression. Behav Genet. 2014;44(6):639-45.

23. McCrae RR, Costa PT. The five-factor theory of personality: theoretical perspective; 1996.

24. Ebstrup JF, Eplov LF, Pisinger C, Jørgensen T. Association between the five factor personality traits and perceived stress: is the effect mediated by general self-efficacy? Anxiety Stress Coping. 2011;24(4):407-19.
25. Brown TA, Naragon-Gainey K. Evaluation of the unique and specific contributions of dimensions of the triple vulnerability model to the prediction of DSM-IV anxiety and mood disorder constructs. Behav Ther. 2013;44(2):277-92.

26. van der Wal RA, Bucx MJ, Hendriks JC, Scheffer GJ, Prins JB. Psychological distress, burnout and personality traits in Dutch anaesthesiologists: a survey. Eur J Anaesthesiol. 2016;33(3):179-86.

27. Kim SE, Kim H-N, Cho J, Kwon M-J, Chang Y, Ryu S, Shin H, Kim H-L. Direct and indirect effects of five factor personality and gender on depressive symptoms mediated by perceived stress. PLoS One. 2016;11(4):e0154140.

28. Gramstad TO, Gjestad R, Haver B. Personality traits predict job stress, depression and anxiety among junior physicians. BMC Med Educ. 2013;13:150.

29. Wang S, Blazer DG. Depression and cognition in the elderly. Annu Rev Clin Psychol. 2015;11:331-60.

30. Aggarwal NT, Wilson RS, Beck TL, Rajan KB, Mendes de Leon CF, Evans DA, Everson-Rose SA. Perceived stress and change in cognitive function among adults 65 years and older. Psychosom Med. 2014;76(1):80-5.

31. Gutzmann H, Qazi A. Depression associated with dementia. Z Gerontol Geriatr. 2015;48(4):305-11.

32. Bennett $\mathrm{S}$, Thomas AJ. Depression and dementia: cause, consequence or coincidence? Maturitas. 2014;79(2):184-90.

33. Byers AL, Yaffe K. Depression and risk of developing dementia. Nat Rev Neurol. 2011;7(6):323-31.

34. Phibbs S, Stawski RS, MacDonald SWS, Munoz E, Smyth JM, Sliwinski MJ. The influence of social support and perceived stress on response time inconsistency. Aging Ment Health. 2019;23(2):214-21.

35. Kuzma E, Sattler C, Toro P, Schönknecht P, Schröder J. Premorbid personality traits and their course in mild cognitive impairment: results from a prospective population-based study in Germany. Dement Geriatr Cogn Disord. 2011;32(3):171-7.

36. Mendez Rubio M, Antonietti JP, Donati A, Rossier J, von Gunten A. Personality traits and behavioural and psychological symptoms in patients with mild cognitive impairment. Dement Geriatr Cogn Disord. 2013;35(1-2):87-97.

37. Terracciano A, Stephan Y, Luchetti M, Albanese E, Sutin AR. Personality traits and risk of cognitive impairment and dementia. J Psychiatr Res. 2017;89:22-7.

38. Curtis RG, Windsor TD, Soubelet A. The relationship between Big-5 personality traits and cognitive ability in older adults - a review. Neuropsychol Dev Cogn B Aging Neuropsychol Cogn. 2015;22(1):42-71.

39. Munoz E, Stawski RS, Sliwinski MJ, Smyth JM, MacDonald SWS. The ups and downs of cognitive function: neuroticism and negative affect drive performance inconsistency. J Gerontol B Psychol Sci Soc Sci. 2018. https:// doi.org/10.1093/geronb/gby1032.

40. Cohen S, Kamarck T, Mermelstein R. A global measure of perceived stress. J Health Soc Behav. 1983;24(4):385-96.

41. Wongpakaran N, Wongpakaran T. The Thai version of the PSS-10: an investigation of its psychometric properties. Biopsychosoc Med. 2010;4:6-6.

42. Wongpakaran $\mathrm{T}$, Wongpakaran $\mathrm{N}$. The effect of neuroticism on academic performance and quality of life in third-year medical students, Chiang Mai University. Chaing Mai: Chaing Mai University; 2013.

43. Hemrungrojn S.Thaiversion of Montreal Cognitive Assessment. 2011. Available from: www.mocatest.org. Accessed 10 June 2013.

44. Nasreddine Z, Phillips N, Bédirian V, Charbonneau S, Whitehead V, Collin I, Cummings J, Chertkow H. The Montreal Cognitive Assessment, MoCA: a brief screening tool for mild cognitive impairment. J Am Geriatr Soc. 2005;53(4):695-9.

45. Tangwongchai $S$, Charernboon T, Phanasathit M. The validity of Thai version of the Montreal cognitive assessment. Dement Neuropsychol. 2009;3(2):136-78.

46. Boongird P. Mental State Examination T10. Dementia Association of Thailand Newsletter Vol. 10. 2018. https://thaidementia.com/news/assets/ files/DAT_news_letter_10.pdf. Accessed 17 Jan 2020.

47. Shiekh J, Yesavage J. Geriatric Depression Scale (GDS): recent evidence and development of a shorter version. In: Brink T, editor. Clinical gerontology: a guide to assessment and intervention. New York: The Haworth Press; 1986.

48. Wongpakaran N, Wongpakaran T, Van Reekum R. The use of GDS-15 in detecting MDD: a comparison between residents in a Thai long-term care home and geriatric outpatients. J Clin Med Res. 2013;5(2):101-11.

49. Nunnally JC, Bernstein IH. Psychometric theory. 3rd ed. New York: McGrawHill, Inc; 1994.

50. Clark LA, Watson D, Mineka S. Temperament, personality, and the mood and anxiety disorders. J Abnorm Psychol. 1994;103(1):103-16.

51. Watson D, Gamez W, Simms LJ. Basic dimensions of temperament and their relation to anxiety and depression: a symptom-based perspective. J Res Pers. 2005;39(1):46-66. 
52. Klatzkin RR, Dasani R, Warren M, Cattaneo C, Nadel T, Nikodem C, Kissileff HR. Negative affect is associated with increased stress-eating for women with high perceived life stress. Physiol Behav. 2019;210:112639.

53. Whitehead BR, Bergeman CS. Coping with daily stress: differential role of spiritual experience on daily positive and negative affect. J Gerontol B Psychol Sci Soc Sci. 2012;67(4):456-9.

54. Manning K, Paulus DJ, Hogan JBD, Buckner JD, Farris SG, Zvolensky MJ. Negative affectivity as a mechanism underlying perceived distress tolerance and cannabis use problems, barriers to cessation, and self-efficacy for quitting among urban cannabis users. Addict Behav. 2018;78:216-22.

55. Steffens DC, Wu R, Grady JJ, Manning KJ. Presence of neuroticism and antidepressant remission rates in late-life depression: results from the Neurobiology of Late-Life Depression (NBOLD) study. Int Psychogeriatr. 2018;30(7):1069-74.

56. Suradom C, Wongpakaran N, Wongpakaran T, Lerttrakarnnon P, Jiraniramai S, Taemeeyapradit U, Lertkachatarn S, Arunpongpaisal S. Prevalence and associated factors of comorbid anxiety disorders in late-life depression: findings from geriatric tertiary outpatient settings. Neuropsychiatr Dis Treat. 2019;15:199-204.

57. Ettema RG, Van Koeven H, Peelen LM, Kalkman CJ, Schuurmans MJ. Preadmission interventions to prevent postoperative complications in older cardiac surgery patients: a systematic review. Int J Nurs Stud. 2014;51(2): 251-60.

58. Yao C, Stawski RS, Hultsch DF, MacDonald SWS. Selective attrition and intraindividual variability in response time moderate cognitive change. J Clin Exp Neuropsychol. 2016;38(2):227-37.

59. Graham EK, Lachman ME. Personality traits, facets and cognitive performance: age differences in their relations. Personal Individ Differ. 2014; 59:89-95.

60. Roberts BW, Walton KE, Viechtbauer W. Patterns of mean-level change in personality traits across the life course: a meta-analysis of longitudinal studies. Psychol Bull. 2006;132(1):1-25.

61. Helson R, Kwan VSY, John OP, Jones C. The growing evidence for personality change in adulthood: findings from research with personality inventories. J Res Pers. 2002:36(4):287-306.

62. Suls J, Martin R. The daily life of the garden-variety neurotic: reactivity, stressor exposure, mood spillover, and maladaptive coping. J Pers. 2005; 73(6):1485-510.

63. Gaynor ST. Temporal precedence in the identification of mediators of change: a brief comment on "mediators of change in the child/adolescent multimodal treatment study" (Kendall et al., 2016). Consult Clin Psychol. 2017:85(1):77-9.

64. Helvik A-S, Barca ML, Bergh S, Šaltytè-Benth J, Kirkevold Ø, Borza T. The course of depressive symptoms with decline in cognitive function - a longitudinal study of older adults receiving in-home care at baseline. BMC Geriatr. 2019;19(1):231.

65. Sherman DS, Mauser J, Nuno M, Sherzai D. The efficacy of cognitive intervention in mild cognitive impairment (MCl): a meta-analysis of outcomes on neuropsychological measures. Neuropsychol Rev. 2017;27(4): $440-84$

\section{Publisher's Note}

Springer Nature remains neutral with regard to jurisdictional claims in published maps and institutional affiliations.

\section{Ready to submit your research? Choose BMC and benefit from:}

- fast, convenient online submission

- thorough peer review by experienced researchers in your field

- rapid publication on acceptance

- support for research data, including large and complex data types

- gold Open Access which fosters wider collaboration and increased citations

- maximum visibility for your research: over $100 \mathrm{M}$ website views per year

At $\mathrm{BMC}$, research is always in progress.

Learn more biomedcentral.com/submissions 